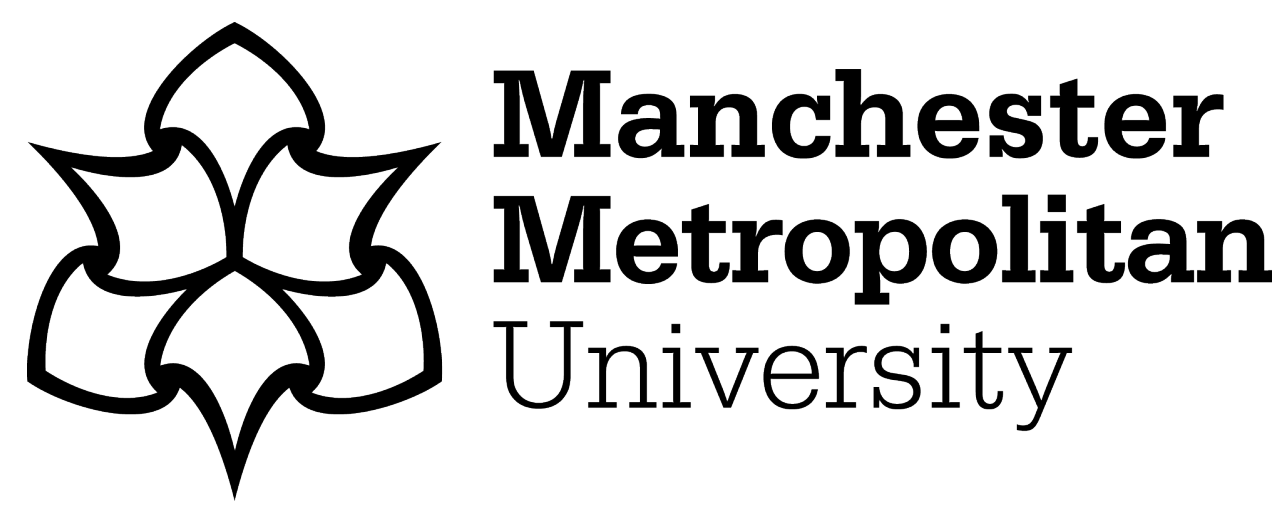

Georgieva, Irina, Whittington, Richard, Lauvrud, Christian, Steinert, Tilman, Wikman, Sofia, Lepping, Peter, Duxbury, Joy ORCID logoORCID: https://orcid.org/0000-0002-1772-6874, Snorrason, Jon, Mihai, Adriana, Berring, Lene Lauge, BN, Raveesh and Vesselinov, Roumen (2019) International variations in mental-health law regulating involuntary commitment of psychiatric patients as measured by the Mental Health Legislation Attitudes Scale. Medicine, Science and the Law, 59 (2). pp. 104-114. ISSN 0025-8024

Downloaded from: https://e-space.mmu.ac.uk/622811/

Version: Accepted Version

Publisher: SAGE Publications

DOI: https://doi.org/10.1177/0025802419841139

Please cite the published version 


\title{
International variations in mental-health law regulating involuntary commitment of psychiatric patients as measured by the Mental Health Legislation Attitudes Scale
}

\author{
Irina Georgieva ${ }^{1}$, Richard Whittington ${ }^{2,3,4}$, Christian Lauvrud ${ }^{2}$, \\ Tilman Steinert ${ }^{5,6}$, Sofia Wikman ${ }^{7}$ C, Peter Lepping ${ }^{8,9,10}$, \\ Joy Duxbury ${ }^{11}$, Jon Snorrason ${ }^{12}$, Adriana Mihai ${ }^{13}$, \\ Lene Lauge Berring ${ }^{14,15}$, Raveesh $\mathrm{BN}^{16}$ and \\ Roumen Vesselinov ${ }^{17}$
}

\begin{abstract}
Previous research illustrated that the laws regulating involuntary placement and treatment of people with mental-health problems are diverse across countries. International studies comparing satisfaction levels between countries are rare. We compared the opinions of professionals and family members about the operation of the national mental-health law regulating forcibly admission and treatment of psychiatric patients in 11 countries: Ireland, Iceland, England and Wales, Romania, Slovenia, Denmark, Germany, Sweden, Norway and India. An online survey design was adopted using a Mental Health Legislation Attitudes Scale (MHLAS). This brief nine-item questionnaire was distributed via email to psychiatrists, general practitioners, acute and community mental-health nurses, tribunal members, police officers and family members in each collaborating country. The levels of agreement/disagreement were measured on a Likert scale. Data were analysed both per question and with regard to a total MHLAS 'approval' score computed as a sum of the nine questions. We found that respondents in England and Wales and Denmark expressed the highest approval for their national legislation (76\% and $74 \%$, respectively), with those in India and Ireland expressing the lowest approval (65\% and 64\%, respectively). Almost all countries had a more positive attitude in comparison to Ireland on the admission criteria for involuntary placement and the way people are transferred to psychiatric hospitals. There are significant variations across Europe and beyond in terms of approval for how the national mental-health law framework operates in each country.
\end{abstract}

Keywords

Involuntary admission, mental-health law, international comparison, legislation, psychiatry, compulsory hospitalisation

\footnotetext{
${ }^{1}$ Independent Researcher, Bulgaria

${ }^{2}$ St Olav's University Hospital, Forensic Department Brøset Centre for Research and Education in Forensic Psychiatry, Norway

${ }^{3}$ Norwegian University of Science and Technology, Faculty of Medicine, Department of Neuroscience, Norway

${ }^{4}$ University of Liverpool, UK

${ }^{5}$ Ulm University, Clinic for Psychiatry and Psychotherapy I, Germany

${ }^{6}$ Centres for Psychiatry Sued Wuerttemberg, Ulm University, Germany

7 University of G€avle, Department of Social Work and

Psychology, Sweden

${ }^{8}$ Centre for Mental Health and Society, Bangor University, UK

${ }^{9}$ Mysore Medical College and Research Institute, India
}

${ }^{10}$ Betsi Cadwaladr University Health Board, Liaison Psychiatry, Wrexham Maelor Hospital, UK

${ }^{11}$ Manchester Metropolitan University, UK

12University Hospital of Iceland, Department of Psychiatry, Iceland

${ }^{13}$ University of Medicine and Pharmacy Tg Mures, Romania

${ }^{14}$ Psychiatric Research Unit, Denmark

${ }^{15}$ Faculty of Health, University of Southern Denmark, Denmark

${ }^{16}$ Department of Psychiatry, Mysore Medical College and

Research Institution, India

${ }^{17}$ University of Maryland, USA

Corresponding author:

Irina Georgieva, Independent Researcher, Sofia, Bulgaria.

Email: irinageorgieva@hotmail.com 


\section{Introduction}

Involuntary detention and treatment for mental-health problems is a potentially controversial procedure, which is often justified for both therapeutic reasons and public protection. Although coercion can be ben-eficial when risk to self or others is a serious issue, it can also adversely impact upon a person's state of mind and severely impair their psychological well-being. The legislation that governs the admission and management of mentally ill people in each country should comply with the standards set by the United Nations Convention on the Rights of Persons with Disabilities ${ }^{1}$ in order to ensure balance between patients' human rights and their need and right for treatment, and public safety. However, despite the efforts of the World Health Organization to standard-ise strategies for the delivery of mental health-care internationally, previous research has shown that the legal frameworks in this area are diverse across coun-tries, ${ }^{2}$ even when the countries are culturally and geo-graphically similar. For example, the procedures for involuntary commitment and involvement of stake-holders in the initiation and decision-making process vary across countries. Also, while most legal frame-works include dangerousness criteria in various forms, the need for treatment in the best interests of the patient, regardless of dangerousness, is sufficient to detain individuals irrespective of risk in some coun-tries ${ }^{3-5}$ such as Sweden. An overview of the varying legal frameworks in the 11 countries included in this study, based on consultation with national experts, is provided in Table 1.

Compulsory admission rates per 100,000 population vary remarkably across Europe, ranging from six per year in Portugal to 218 per year in Finland. ${ }^{6}$ This strongly suggests that differences in definitions, legal backgrounds or procedures contribute to variations in detention rates and mental-health service delivery. ${ }^{7}$

In order to improve national legislation globally and to prevent the excessive application of compulsory procedures in some countries, an evidence-based interna-tional debate is needed to facilitate shared learning and opportunities for service improvement. This could lead to the development of a consensus across countries on the best legal practices and then to harmonisation of legislation and practice across the European Union and worldwide to reflect these benchmarks. A recent report issued by the European Union Agency for Fundamental Rights confirmed this need for a renewed discussion about compulsory placement and treatment in the region. ${ }^{8}$ In line with this, Mulder ${ }^{9}$ has also sug-gested that international collaborative working groups should be established urgently to investigate and compare legal practices across countries to support these initiatives.

Despite these appeals, international comparative studies in this field are rare. A previous study compar-ing attitudes of mental-health professionals and lay people towards involuntary admission and treatment from England and Germany by using scenarios of potentially detainable patients found that the different legal frameworks did not influence attitudes much. ${ }^{10}$ Another comparative review questioned whether vari-ous European laws on compulsory commitment to care in relation to substance use disorder or misuse prob-lems comply with international ratified conventions concerning human and civil rights. ${ }^{11}$ However, interna-tional comparative studies among stakeholders with direct experience of the process, such as professionals and family members, across several countries, covering different legal aspects and procedures are still lacking.

Therefore, this study was designed to compare the opinions of professionals and family members about the operation of the national mental-health law regu-lating forcibly admission and treatment of psychiatric patients in 11 countries: Ireland, Iceland, England and Wales, Romania, Slovenia, Denmark, Sweden, Germany, Norway and India.

\section{Methods}

\section{Instrument}

An online survey design was adopted using a Mental Health Legislation Attitudes Scale (MHLAS), a brief nine-item questionnaire developed by an interdisciplin-ary group for a previous study. ${ }^{12}$ Questions were phrased in such a way so that the same questions could be answered by the different stakeholders despite their different professional roles and experiences as fol-lows: Q1 (treatment efficacy) The legislation operates well in ensuring treatment for persons that require involuntary admission; Q2 (admission criteria) The clinical assessment in order to meet the criteria for involuntary admission works well under the legislation; Q3 (care benefits) People admitted without their con-sent generally benefit from the care received; Q4 (con-sent to treatment) Where possible the legislation supports the person's right to consent to or refuse treat-ment; Q5 (detention review) The legislation ensures an independent and fair review of the person's detention; Q6 (implementation of the law) The legislation is diffi-cult to implement in practice; Q7 (information about the law) Information about the legislation is not readily available; Q8 (transfer to hospital) The way in which people are transferred to the inpatient unit works well under the legislation; Q9 (reciprocity principle) People admitted without their consent receive the least 
Table 1. International experts' views on differences in mental-health legislation.

\begin{tabular}{|c|c|c|c|c|c|c|c|c|c|c|}
\hline Country & $\begin{array}{l}\text { Q1. What are } \\
\text { the criteria for } \\
\text { involuntary } \\
\text { placement? }\end{array}$ & $\begin{array}{l}\text { Q2. Diagnoses are } \\
\text { legally defined, } \\
\text { excluding conditions } \\
\text { not sufficient for } \\
\text { involuntary } \\
\text { placement }\end{array}$ & $\begin{array}{l}\text { Q3. Who is } \\
\text { responsible for the } \\
\text { initial assessment } \\
\text { before transfer to } \\
\text { psychiatric facility? }\end{array}$ & $\begin{array}{l}\text { Q4. Who has the } \\
\text { authority to decide on } \\
\text { involuntary placement } \\
\text { and how many experts } \\
\text { are involved in the } \\
\text { assessment? }\end{array}$ & $\begin{array}{l}\text { Q5. Involuntary } \\
\text { placement and } \\
\text { treatment are legally } \\
\text { defined as different } \\
\text { modalities } 1 \\
\text { (yes or no) }\end{array}$ & $\begin{array}{l}\text { Q6. Detailed } \\
\text { regulation } \\
\text { of coercive } \\
\text { measures } \\
\text { (yes or no) }\end{array}$ & $\begin{array}{l}\text { Q7. Compulsory } \\
\text { outpatient treatment } \\
\text { possible (i.e. } \\
\text { community } \\
\text { treatment } \\
\text { orders; yes or no) }\end{array}$ & $\begin{array}{l}\text { Q8. Priority of } \\
\text { less restrictive } \\
\text { alternatives }{ }^{2} \text { is } \\
\text { explicitly mentioned } \\
\text { in the legislation } \\
\text { (yes or no) }\end{array}$ & $\begin{array}{l}\text { Q9. Patients are } \\
\text { transferred } \\
\text { to psychiatric } \\
\text { hospital by... }\end{array}$ & $\begin{array}{l}\text { Q10. Independent } \\
\text { review of patients' } \\
\text { detention is legally } \\
\text { required (yes or no) }\end{array}$ \\
\hline Ireland & $\mathrm{T}$ or $\mathrm{D}$ & Wide; PD, A & GP & Two psychiatrists; 2 & No & No & No & Yes & $P, F, O P S$ & Yes \\
\hline Sweden & $\mathrm{T}$ & n.d. & GP, $P$ & GP and psychiatrist; 2 & Yes & Yes & Yes & Yes & $F, P, E, O P S$, IPS & Yes \\
\hline Germany & $\mathrm{D}$ & Wide & $\begin{array}{l}\text { Any doctor, } \\
\text { police }\end{array}$ & Judge and psychiatrist; 2 & Yes & Yes & No & Yes & No clear regulation & Yes (judge) \\
\hline Denmark & $\mathrm{T}$ or $\mathrm{D}$ & Not defined & Doctor & Psychiatrist and GP; 2 & Yes & Yes & $\begin{array}{l}\text { Yes, if certain } \\
\text { criteria } \\
\text { are fulfilled }\end{array}$ & Yes & $\mathrm{P}$ & Yes \\
\hline $\begin{array}{l}\text { England } \\
\text { and Wales }\end{array}$ & $\mathrm{T}$ or $\mathrm{D}$ & $\begin{array}{l}\text { Wide, PD } \\
\text { included }\end{array}$ & $\begin{array}{l}\text { Doctor, } \\
\text { AMHP, GP }\end{array}$ & $\begin{array}{l}\text { Doctor \& AMHP, } 2 \text { or } 3 \\
\text { depending on type } \\
\text { of detention }\end{array}$ & Yes & No & Yes & Yes & $\mathrm{P}, \mathrm{AMHP}$ & Yes \\
\hline Slovenia & $\mathrm{D}$ & n.d. & Doctor, $\mathrm{P}$ & Judge and psychiatrist, 2 & No & Yes & No & Yes & $P, E, I P S$ & $\begin{array}{l}\text { No, but patient can } \\
\text { appeal against } \\
\text { detention }\end{array}$ \\
\hline Romania & $\mathrm{D}$ & n.d. & $\mathrm{GP}, \mathrm{P}$ & $\begin{array}{l}\text { Two psychiatrists and } \\
\text { one doctor from other } \\
\text { specialty, } 3\end{array}$ & Yes & Yes & No & Yes & $P, F, E$, OPS, IPS & Yes \\
\hline Iceland & $\mathrm{T}$ or $\mathrm{D}$ & Wide & $\begin{array}{l}\text { Any doctor, } \\
\text { GP, police }\end{array}$ & Psychiatrist, 1 & Yes & No & No & Yes & $P, F, O P S$ & $\begin{array}{l}\text { No, but patient } \\
\text { can appeal } \\
\text { against detention }\end{array}$ \\
\hline Norway & $\mathrm{T}$ or $\mathrm{D}$ & Wide & GP, P & GP and psychiatrist; 2 & Yes & Yes & Yes & Yes & $\mathrm{F}, \mathrm{P}, \mathrm{E}, \mathrm{OPS}, \mathrm{IPS}$, any & Yes \\
\hline India & $\mathrm{T}$ or $\mathrm{D}$ & n.d. & GP & $\begin{array}{l}\text { Psychiatrist and medical } \\
\text { officer, }{ }^{3} 2\end{array}$ & Yes & No & No & No & $F, P, E, O P S, I P S$ & $\begin{array}{l}\text { No, but a board } \\
\text { of visitors inspects } \\
\text { IPS every month }\end{array}$ \\
\hline
\end{tabular}

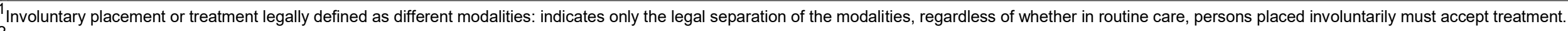

${ }^{2}$ Priority of less restrictive alternatives: underlines that coercive measures is an 'ultima ratio', prerequisite hereto is the availability of facilities offering less restrictive.

${ }^{3}$ Medical officers only have a medical degree, and they replace psychiatrists sometimes due to the severe shortage of psychiatrists in India.

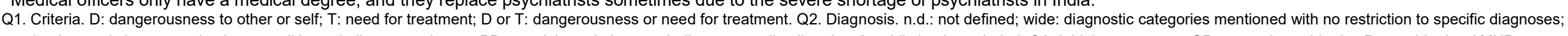

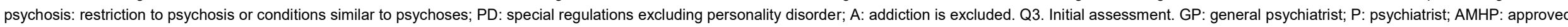

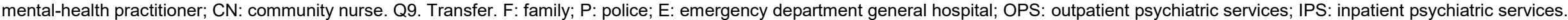


restrictive and the most effective care available under the circumstances.

Survey participants were requested to express their levels of agreement or disagreement with the questions listed above about their national legislation on a five-point Likert scale, with high values indicating positive attitudes (including two items, Q6 and Q7, which were reverse scored for the analysis below). Details of indi-vidual items are reported in the results below. Each item also had a space for an optional free-text response for further elaboration in addition to the Likert-scale response. However, these qualitative responses will be addressed in a follow-up study.

\section{Procedure and participants}

The questionnaire was distributed using the Survey Monkey! online software. The survey link was sent to an expert contact in each of the nine countries in Europe (Denmark, Germany, Iceland, Ireland, Norway, Romania, Slovenia, Sweden and England and Wales) plus India after obtaining ethical approval in Ireland, Iceland and England and Wales. The other countries did not require healthservice ethical approv-al for surveys involving staff and family members. We decided to merge responses from England and Wales, because these countries have a common legislation and both form part of the UK. Expert contacts were mem-bers of an international research group and included psychiatrists, mental-health nurses and psychologists. They were asked to identify relevant networks in their country representing caregivers and three professional groups which are involved in the application of the mental-health laws: medical practitioners (general practitioners and psychiatrists), mental-health nurses (acute inpatient or community settings) and criminal justice/legal professionals (solicitors, tribunal members and police officers). The national contact in each coun-try then distributed the link onward via email to the identified networks with a request for forwarding to all registered members of the organisation mailing list. In order to collect sufficient data, we sent reminders peri-odically to stakeholders. Data collection took one year from December 2014 until December 2015.

Potential respondents received the link and a brief introduction to the study. If they agreed to enter the study site, they were presented with an online informa-tion sheet and consent form prior to accessing the ques-tions. Items had to be answered in the presented order, and each item could not be left blank before proceeding to the next item. Basic demographic and other data were also requested (stakeholder group, sex, age, number of years in current profession and number of involuntary admissions the person participated in or experienced as a professional or family member). The introductory text specified that respondents were only eligible to participate if they were a close family member of a person who had been previously detained or they worked in a professional role in one of three categories mentioned above.

\section{Analyses}

Anonymised responses were logged directly on the Survey Monkey website during completion in a passwordprotected area. The completed data set was downloaded by the lead researcher into Microsoft Excel format and then exported into IBM SPSS Statistics for Windows v25 (IBM Corp., Armonk, NY) for analysis. Data were analysed both per item/ question and with regard to a total MHLAS 'approval' score computed as a sum of the nine items (including the two which were reverse scored). Only respondents with valid answers to all nine questions were included in the total score analysis, and these scores were recoded into a $0-100$ scale.

It is not possible to specify a response rate, as the number of potential participants who received the link is not known. Multiple regression was used for the total score analysis. Regression models were tested to exam-ine the relationship between country of residence and demographic factors as independent variables poten-tially predictive of satisfaction with the national mental-health law as the dependent variable.

In addition, ordinal logistic regression was used for individual item analysis. Associations were expressed as cumulative odds ratios (ORs) with Irish respondents as the reference group based on the original paper, ${ }^{9}$ also controlling for the effect of country of residence and demographic factors.

\section{Results}

\section{Sample description}

Responses were received from 2616 professionals and family members varying between countries as follows:

Denmark (n $1 / 470)$, Germany (n $1 / 4558)$, Iceland (n 1/4 230), Ireland (n 1/4 503), Norway (n 1/4 284), Romania (n $1 / 4128)$, Slovenia (n $1 / 4120)$, Sweden (n $1 / 4$ 423), England and Wales (n $1 / 4$ 102) and India ( $n \frac{1}{4}$ 198). The modal age category of the respondents was 40-49 years, with 53\% being female. About 33\% were doctors, $29 \%$ were nurses, $23 \%$ were police or tribunal members and $16 \%$ were family members. The vast majority $(92.2 \%)$ of the respondents had some experience with involuntary admissions.

Completion rates per item were as follows: Q1, 2135 (81.5\%); Q2, 1616 (61.7\%); Q3, 1578 (60.2\%); Q4, 1958 (74.7\%); Q5, 1913 (72.6\%); Q6, 2011 (76.8\%); 
Table 2. Level of satisfaction per question.

\begin{tabular}{|c|c|c|c|c|c|c|c|c|c|c|}
\hline Country & Q1 & Q2 & Q3 & Q4 & Q5 & Q6 & Q7 & Q8 & Q9 & Overall satisfaction \\
\hline 1. Denmark & 53 & 68 & 74 & 65 & 78 & 52 & 80 & 61 & 51 & 74 \\
\hline 2. Iceland & 67 & 63 & 60 & 45 & 53 & 41 & 53 & 32 & 51 & 68 \\
\hline 3. India & 60 & 60 & 81 & 53 & 53 & 27 & 32 & 53 & 49 & 65 \\
\hline 4. Germany & 44 & 56 & 66 & 72 & 54 & 34 & 52 & 53 & 41 & 66 \\
\hline 5. Norway & 56 & 49 & 69 & 65 & 55 & 36 & 44 & 37 & 39 & 67 \\
\hline 6. Romania & 62 & 55 & 87 & 69 & 53 & 24 & 31 & 43 & 54 & 66 \\
\hline 7. Slovenia & 27 & 42 & 79 & 73 & 65 & 22 & 69 & 78 & 76 & 69 \\
\hline 8. Sweden & 61 & 64 & 58 & 59 & 60 & 48 & 70 & 43 & 47 & 70 \\
\hline 9. England and Wales & 73 & 75 & 85 & 69 & 85 & 64 & 72 & 50 & 61 & 76 \\
\hline 10. Ireland & 53 & 38 & 77 & 56 & 64 & 36 & 51 & 23 & 44 & 64 \\
\hline Total & 54 & 54 & 70 & 62 & 59 & 38 & 54 & 44 & 47 & 68 \\
\hline
\end{tabular}

Table shows percent of respondents approving (i.e. 'agree' or 'strongly agree') each aspect of the current mental-health law by country.

Q7, 2004 (76.5\%); Q8, $1777(67.8 \%) ;$ and Q9, $1671(63.8 \%)$

For the following analyses, we excluded from the sample 328 participants who did not have any experi-ence with involuntary admissions or did not answer any of the above listed items.

\section{Level of satisfaction}

In order to estimate the level of satisfaction with the mental-health legislation per country, we recoded the responses as either approving the mental-health law (i.e. 'agree' or 'strongly agree' with the statement) or not approving (i.e. 'neither agree nor disagree', 'dis-agree' or 'strongly disagree'). We found that the ques-tion which received highest approval rate across all countries was about the care benefits of the law (Q3), and the lowest approval rate concerned the implemen-tation of the legislation (Q6; see Table 2). Responses clearly varied per question and country. The average overall approval rate for the current mental-health law across all 11 countries was about $68 \%$. The countries with the highest overall satisfaction were England and Wales (76\%) followed closely by Denmark (74\%), and the most dissatisfied country was Ireland (64\%). The actual average scores for each item varied from 2.9 for Q6 ('implementation of the legislation') to 3.8 for Q3 ('care benefits'), with an overall average score of 3.4 out of 5 .

\section{Multivariate analysis for factors affecting participants' overall satisfaction}

Scale reliability. We then treated the nine questions as a scale (MHLAS). Its internal reliability was very high (Cronbach's a 1/4 0.808). Based on this good scale reliability, we constructed an overall total score as the sum of all nine questions and transformed it into a 100-point scale by dividing the total score for each respondent by the maximum possible score. An overall score of 100 here would mean that all nine questions were answered with the maximum individual score of 5 (i.e. 'strongly agree'). A high score indicates strong satisfaction, and a low score indicates poor satisfaction. In order to preserve the integrity and meaningfulness of this measure for all further analyses, we included only respondents with valid answers to all nine questions, which resulted in 1444 respondents for the multivari-ate analysis.

Country comparison by overall levels of satisfaction. The mean MHLAS total score by country is presented in Figure 1. Respondents in England and Wales and Denmark expressed the highest approval for their national legislation, and those in India and Ireland expressed the lowest approval. We compared these mean satisfaction levels for all 10 countries with the analysis of variance (ANOVA) test for significant differences and Tukey's post hoc adjustment for multiple comparisons. This analysis confirmed that there are statistically significant differences in the satisfaction with the current mental-health law between the 11 countries (ANOVA F-test $1 / 47.3$, df $1 / 4$ 9,14, $p<0.001$ ).

Country classification. We built a classification and regression tree (CART) model to determine the most signif-

icant breaks in the trend and to create meaningfully distinct groups. ${ }^{13,14}$ The CART model discovered

four different groups of satisfaction with the current mental-health law: group 1 (with the lowest satisfac-tion): Ireland and India; group 2: Germany, Norway and Romania; group 3: Iceland, Slovenia and Sweden; and group 4 (with the highest satisfaction): England and Wales and Denmark. 


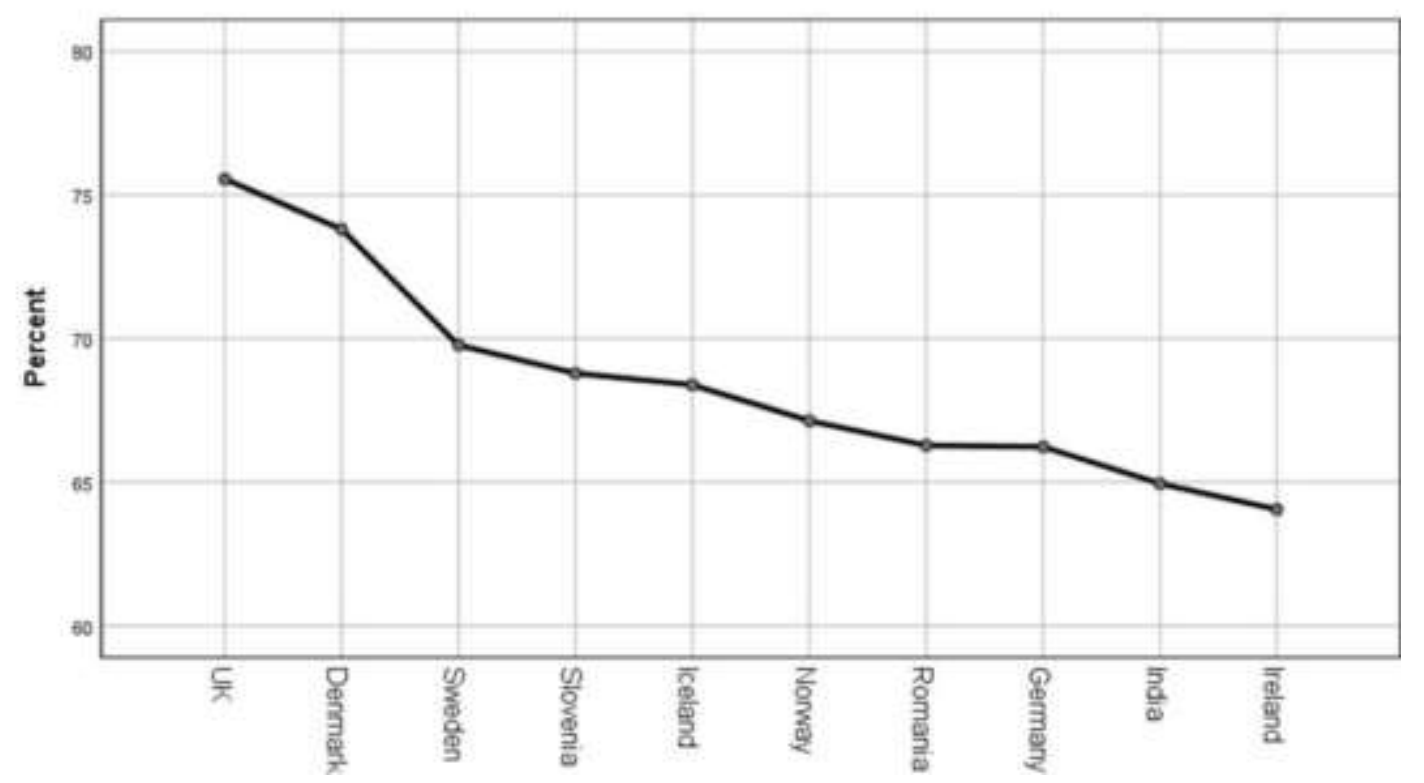

Figure 1. Overall satisfaction with the current mental-health law (percent). $100 \% 1 / 4$ fully satisfied with current mental-health law.

Factors for overall satisfaction with the current mentalhealth law. We then performed initial statistical testing on fac-tors potentially affecting the degree of overall satisfaction (MHLAS total score). Demographic characteristics (sex and age) and overall work experi-ence had no association with overall satisfaction. However, the respondents' experience with involuntary admissions did have a significant effect (ANOVA F-test $1 / 426.5$, df $1 / 42,14$, $p<0.001)$ in that the more experi-ence the person had with admissions, the more satisfied they were overall with the mental-health law in their country.

Respondents' professions also had a significant effect on satisfaction (ANOVA F-test 1/4 37.2, df 1/4 3,14, p <.001). Doctors and nurses were relatively more satisfied with the legislation (68\% and $71 \%$, respectively) compared to the police $(63 \%)$ and family members $(63 \%)$. The difference between doctors and nurses on the one hand and police and family on the other was statistically significant.

We then adopted the overall satisfaction (MHLAS total score) as the outcome variable and used the avail-able independent variables to build a multivariate model (see Table 3). Overall work experience was excluded from the model a priori because family mem-bers were not asked this question.

When controlling for demographics, the number of involuntary admissions experienced and profession, some differences between the countries remained intact, while others became or remained not significant.

Sex and age had no effect on overall satisfaction with the current mental-health law in this model. Experience with admission did have an effect though in that as in the univariate analysis, greater experience was associated with higher satisfaction when the other variables in the model were held constant. Doctors and nurses tended to have significantly greater satisfaction than family members, while the satisfaction level of criminal justice professionals was not distinguishable from that of family members. The key finding from the multivariate models was that most inter-country differences remain statistically significant, even after controlling for demographics and other important fac-tors (see Table 4).

Evaluating satisfaction based on the individual questions.

Another way to investigate differences in satisfaction with the mental-health law between countries is to compare responses to the individual MHLAS items using ordinal regression. ${ }^{15}$ We built nine separate ordi-nal regression models (one for each item), using Ireland as a reference group in all analyses. This approach was used due to the prior reporting of Irish data as noted above. ${ }^{16}$ In each model, we included a control block of sex, age, profession and experience with admissions. The main results with reference to the country differ-ences compared to Ireland are summarised in Table 5.

For example, looking at the multivariate ordinal regression model for treatment efficacy of mental-health law (Q1) in Table 5, we can say that Iceland, Norway and England and Wales tended to approve of this aspect significantly more strongly than Ireland. On the other hand, Germany and Slovenia had significant-ly lower satisfaction compared to Ireland. India, Romania and Sweden were not statistically different from Ireland on this question. 
It is striking that on Q2 (admission criteria) and Q8 (transfer to hospital), almost all countries had a more positive attitude in comparison with Ireland, whilst on the other items the direction of relative satisfac-tion varied.

Age and sex had an effect on only two items: older people tended to be less satisfied than younger people on Q1 (treatment efficacy), while women tended to be less satisfied than men on Q8 (transfer to hospital).

Experience with admissions had a strong effect on most item responses: the more experience the respon-dent had with involuntary admissions, the more satis-fied they were on all items apart for Q8 (transfer to hospital) which was not significant.

Table 3. Multivariate model of overall satisfaction (0-100\%).

\begin{tabular}{|c|c|c|}
\hline \multirow{2}{*}{$\frac{\text { Factors }}{\text { Constant }}$} & \multicolumn{2}{|c|}{ Coefficient $p$-Value } \\
\hline & 56.0 & $<0.001$ \\
\hline 1. Denmark & 7.7 & $<0.001$ \\
\hline 2. Iceland & 6.5 & $<0.001$ \\
\hline 3. India & -5.2 & 0.003 \\
\hline 4. Germany & -2.0 & 0.111 \\
\hline 5. Norway & 3.6 & 0.012 \\
\hline 6. Romania & -1.0 & 0.58 \\
\hline 7. Slovenia & 1.4 & 0.435 \\
\hline 8. Sweden & 2.7 & 0.036 \\
\hline 9. England and Wales & 8.2 & $<0.001$ \\
\hline 10. Ireland & \multicolumn{2}{|l|}{ Reference } \\
\hline Age (ordinal 1-5) & 0.1 & 0.752 \\
\hline $\begin{array}{l}\text { Sex (female } 1 / 41 \text { ) } \\
\text { Experience with admissions (ordinal 1-3) } \\
\text { Profession }\end{array}$ & $\begin{array}{l}-1.0 \\
-1.9\end{array}$ & $\begin{array}{r}0.172 \\
<0.001\end{array}$ \\
\hline Doctors & 8.4 & $<0.001$ \\
\hline Police/tribunal members & -1.7 & 0.189 \\
\hline Nurses & 4.5 & $<0.001$ \\
\hline Family & \multicolumn{2}{|l|}{ Reference } \\
\hline
\end{tabular}

Professional role had an impact on the level of satisfaction on each item, with doctors and nurses being more satisfied in most of the cases than criminal justice professionals and family members.

\section{Discussion}

This study is the first to examine attitudes towards key aspects of mental-health legislation in a large interna-tional sample with substantial groups of professionals and family members in many countries. Whilst there are clear limitations in terms of self-selecting participa-tion and variations in the proportion of stakeholders in each group across countries, the findings highlight areas of potential good practice. As such, they could be used to inform the improvement of legal practices across countries to protect the fundamental rights better of people with mental-health problems.

With regard to international variations, respondents in three countries (England and Wales, Denmark and Iceland) were relatively satisfied with the operation of their legislation, whilst those in Ireland and India were relatively dissatisfied. These national differences cannot be reduced to regional variations across Europe, how-ever. Iceland and Denmark are both 'Nordic' countries which might explain their similarities, but Norway is also in that region of Europe. It shares many legal and cultural institutions with the other two countries but consistently rated lower satisfaction. This dissatisfac-tion could be partly explained by the relatively high rates of involuntary admission in Norway. ${ }^{17}$ Even more starkly, Ireland and England and Wales have similar ties but are at the opposite end of the scale in terms of satisfaction. India is a geographical and cul-tural outlier in the set of countries studied here, and the relative lack of resources for mental-health care in many parts of that country ${ }^{18}$ may go some way to explain the consistently low rate of satisfaction there in comparison with all of the European countries. It

Table 4. Significant differences between countries based on multivariate models for total MHLAS score (overall approval).

\begin{tabular}{|c|c|c|c|c|c|c|c|c|c|c|}
\hline Factor & $\begin{array}{l}\text { Reference } \\
\text { Denmark }\end{array}$ & $\begin{array}{l}\text { country } \\
\text { Iceland }\end{array}$ & India & Germany & Norway & Romania & Slovenia & Sweden & England and Wales & Ireland \\
\hline 1. Denmark & Ref. & & & & & & & & & \\
\hline 2. Iceland & & Ref. & & & & & & & & \\
\hline 3. India & Less & Less & Ref. & & & & & & & \\
\hline 4. Germany & Less & Less & More & Ref. & & & & & & \\
\hline 5. Norway & Less & & More & More & Ref. & & & & & \\
\hline 6. Romania & Less & Less & More & & Less & Ref. & & & & \\
\hline 7. Slovenia & Less & Less & More & More & & & Ref. & & & \\
\hline 8. Sweden & Less & Less & More & More & & More & & Ref. & & \\
\hline 9. England and Wales & & & More & More & More & More & More & More & Ref. & \\
\hline 10. Ireland & Less & Less & More & & Less & & & Less & Less & Ref. \\
\hline
\end{tabular}

'Less' means less satisfied than the reference country. 'More' means more satisfied than the reference country. 
Table 5. Multivariate ordinal regression models (MHLAS individual items).

\begin{tabular}{|c|c|c|c|c|c|c|c|c|c|}
\hline Outcome & $\begin{array}{l}\text { Q1. Treatment } \\
\text { efficacy }\end{array}$ & $\begin{array}{l}\text { Q2. Admission } \\
\text { criteria }\end{array}$ & $\begin{array}{l}\text { Q3. Care } \\
\text { benefits }\end{array}$ & $\begin{array}{l}\text { Q4. Consent } \\
\text { to treatment }\end{array}$ & $\begin{array}{l}\text { Q5. Detention } \\
\text { review }\end{array}$ & $\begin{array}{l}\text { Q6. Implementation } \\
\text { of the law }\end{array}$ & $\begin{array}{l}\text { Q7. Information } \\
\text { about the law }\end{array}$ & $\begin{array}{l}\text { Q8. Transfer } \\
\text { to hospital }\end{array}$ & $\begin{array}{l}\text { Q9. Reciprocity } \\
\text { principle }\end{array}$ \\
\hline Factor & \multicolumn{9}{|c|}{ Odds ratios (significant only, $p<0.05$ ) } \\
\hline 1. Denmark & & 3.1 & & & 1.9 & 2.0 & 4.9 & 5.0 & \\
\hline 2. Iceland & 2.6 & 4.9 & & & & 2.3 & 2.1 & 3.1 & 1.7 \\
\hline 3. India & & 1.7 & 0.6 & 0.6 & 0.3 & 0.5 & 0.3 & 3.0 & 0.4 \\
\hline 4. Germany & 0.4 & 1.5 & 0.4 & 1.9 & 0.4 & 0.7 & & 3.5 & 0.4 \\
\hline 5. Norway & 1.4 & 2.1 & & 1.5 & 0.7 & 1.6 & & 2.7 & \\
\hline 6. Romania & & 1.7 & & & 0.5 & & 0.4 & 2.7 & \\
\hline 7. Slovenia & 0.3 & & & 2.4 & 0.5 & 0.5 & 2.0 & 9.8 & 2.9 \\
\hline 8. Sweden & & 2.8 & 0.3 & & 0.7 & 1.6 & 2.0 & 2.5 & 0.7 \\
\hline $\begin{array}{l}\text { 9. England } \\
\text { and Wales }\end{array}$ & 2.5 & 4.5 & & & 2.0 & 3.3 & 2.3 & 3.5 & \\
\hline 10. Ireland & Reference & & & & & & & & \\
\hline Age (ordinal 1-5) & 0.9 & & & & & & & & \\
\hline Sex (female $1 / 41$ ) & & & & & & & & 0.8 & \\
\hline $\begin{array}{l}\text { Experience with } \\
\text { admissions } \\
\text { (ordinal 1-3) }\end{array}$ & 1.2 & 1.2 & 1.4 & 1.1 & 1.2 & 1.4 & 1.3 & & 1.2 \\
\hline \multicolumn{10}{|l|}{ Profession } \\
\hline Doctors & 1.8 & 2.1 & 2.3 & 1.6 & 2.4 & 2.2 & 2.5 & 1.9 & 3.1 \\
\hline $\begin{array}{l}\text { Police/tribunal } \\
\text { members }\end{array}$ & & & 0.6 & & & & 1.7 & & \\
\hline Nurses & 1.8 & 1.6 & 1.4 & & 1.5 & 1.7 & 1.9 & 1.8 & 1.9 \\
\hline Family & Reference & & & & & & & & \\
\hline
\end{tabular}


should also be noted that during the study period, the Mental Health Act (MHL) 1987 was in force in India, while a new MHL that takes into account the UN Convention on the Rights of Persons with Disabilities (UN-CRPD) has come into effect since 29 May 2018. Further, our findings of German stakeholders being significantly less satisfied with their legislation in com-parison with other countries (i.e. Iceland, Slovenia, Sweden, Denmark and England and Wales) are in line with recent conclusion that the German federal state laws are still extremely heterogeneous and do not fully comply with the requirements of the UN-CRPD. ${ }^{19}$ It is hoped that analysis of the qualita-tive responses from each country included in the survey will enable these patterns to be more clear-ly understood.

The total score of the MHLAS provides a composite measure of attitudes in this area, and the analysis here indicates relative dissatisfaction amongst respondents in some roles and some countries. Criminal justice system (CJS) professionals (i.e. tribunal members and police) and family members were relatively dissatisfied compared to health-care professional (nurses and doc-tors) on the overall use of the relevant mental-health law in their country and on all but one of the individual items. This presumably reflects the various relation-ships each group has with the unwell person who is being detained and with the systems available to pro-vide the person with care and treatment. The wishes of family members in the crisis situation are likely to vary between those who want more or less robust interven-tion than they actually receive. They may feel the inter-vention was excessive, so their dissatisfaction is on behalf of their relative's human rights or they may con-versely feel the intervention was 'too little too late'. Police officers are likely to aim for the most efficient transfer of the person into the hospital and again will probably vary according to the degree of sympathy they have towards people with mental-health problems. Those who are unsympathetic may regard any involvement as an inappropriate use of their time which could be devoted to other activities seen as more relevant to policing.

Individual item responses enabled us to identify some of the specific areas of relative dissatisfaction. The lowest average score of 2.9 on the way MHLs are implemented into practice shows that most of the countries are struggling with how mental-health serv-ices are organised in order to follow legal requirements. All countries except for Slovenia had a more positive attitude in comparison with Ireland on the admission criteria for involuntary placement. In comparison with other countries, Irish legislation explicitly excludes people suffering from personality disorder or those who are addicted to drugs or intoxicants from involuntary treatment, even if these people pose a danger to themselves or others (see Table 1). These unmet treatment needs may explain why dissatisfaction levels are highest among Irish professionals and family members regarding this aspect of the law.

Furthermore, all countries had a more positive atti-tude in comparison with Ireland on the way people are transferred to psychiatric hospitals. If we take Norway as an example, Norwegian stakeholders' more positive attitude may reflect recent service innovations there. ${ }^{20}$ Although still in its experimental stage, the University Hospital of Bergen implemented the first mental-health service ambulance in 2005 aiming to replace local police as the means for transporting patients to inpa-tient services. Initial evaluations have showed positive results with this service such as less stigmatisation and better access to relevant information.

In addition, we found that access to information about the procedure for involuntary commitment and treatment differs between countries, with stakeholders from Romania, India and Ireland being the least satis-fied with this aspect. We share the opinion of Wyder et al. ${ }^{21}$ that providing patients and their relatives with free and full access to information about the involun-tary admission and treatment process, their rights to appeal and rights of access to their own clinical records may help them to regain personal control over their lives after the disempowering and intrusive experience of involuntary admission and treatment.

Furthermore, it is worth noting that health-care professionals here (nurses and doctors) had significantly more experience with involuntary placements than CJS professionals and family members. We found that the more experience the person had with admis-sions, the more satisfied they were overall with the mental-health law in their country, which could be explained through a process of a cognitive disso-nance. ${ }^{22}$ Health-care professionals who have been repeatedly exposed to the mental discomfort of acting against a patient's expressed wishes may have trans-formed this distress into a more positive view in order to reduce internal tension. This will allow them to execute their professional duties in circumstances they are not able to change by experiencing less psy-chological stress and internal conflict. From a clini-cian's point of view, it is also natural to look at the process from one's own perspective. Previous research has shown that attitudes of psychiatrists and nurses regarding compulsory admission are in keeping with those of the general population in four surveyed European countries, but they are not in keeping with clinicians in those countries who are not involved in the compulsory admission process. ${ }^{23}$ This indicates that clinicians who participate in the compulsory admission process seem to be in line with the public when it comes 
to attitudes, but interestingly not necessarily with the views of family members. Alternatively, mental-health professionals may have more positive attitudes towards the use of legislation because they have experience of its benefits, especially in comparison with the suffering, lack of recovery and life disruption caused by not admitting and treating people in a timely fashion.

We propose that the MHLAS described here can be used as a brief, practical tool for surveying the attitudes of busy people involved in the formal and informal care of people with mental-health problems. It can be com-pleted quickly, and there is evidence of good internal consistency. We recommend that it is used in a wider range of countries not included in this sample to enable comparisons to be made and a global picture of this important topic to be constructed.

A number of study limitations must be acknowl-edged here in order to judge the meaningfulness of the findings. In particular, the participants were a self-selected group who may have particularly strong views (positive or negative) on the issue and do not necessarily represent the wider population of equiva-lent professionals and family members in each country. We therefore fully acknowledge that our samples may not be representative of the entirety of the professional groups surveyed in each country. In addition, we real-ise that the law does not stand apart from the range and quality of services provided in the various coun-tries surveyed, and neither do sociocultural differences in attitudes towards people with a mental disorder and the involuntary admission process, with previous stud-ies showing differences across different EU countries and respective professionals. ${ }^{23}$ The sample in each country reflected the networks of the lead researcher there, leading to highly skewed representation of professional groups across countries. So, there may be a country/profession interaction effect in the sample which must be considered when interpreting the find-ings on either of these variables. This issue was addressed in the regression analyses by including a var-iable indicating the professional group for each partic-ipant. We were unable to survey patients because of the way the study was designed, but future research should specifically take into account patients' views.

Finally, it should be noted that high satisfaction does not necessarily equate to best practice. Satisfaction with the process may be based on priorities far removed from the needs of the patient such as bureaucratic simplicity or personal interests. The degree to which it can be inferred that the relative approval for mental health law in England and Wales, Iceland and Denmark indicates these countries have the 'best practice' is questionable and should not be interpreted simplistically.

\section{Conclusion}

There are significant variations across Europe and beyond in terms of approval for how the national mental-health law framework operates in each country. The MHLAS can be used to study these variations and to contribute to improved practice in this challenging area.

\section{Declaration of conflicting interests}

The authors declared no potential conflicts of interest with respect to the research, authorship and/or publication of this article.

\section{Funding}

The authors received no financial support for the research, authorship and/or publication of this article.

\section{ORCID iD}

Sofia Wikman (D http://orcid.org/0000-0002-8186-3662

\section{References}

1. UN General Assembly. Convention on the Rights of Persons with Disabilities [A/RES/61/106]. Resolution adopted by the General Assembly. 2007.

2. Freeman M and Pathare S. WHO resource book on mental health, human rights and legislation. Geneva: World Health Organization, 2005.

3. Zhang S, Mellsop G, Brink J, et al. Involuntary admis-sion and treatment of patients with mental disorder. Neurosci Bull 2015;31:99-112.

4. Salize J, Dresing H and Peitz M. Compulsory admission and involuntary treatment of mentally ill patients - legislation and practice in EU-member states. Available at: http://ec. europa.eu/health/ph_projects/2000/promotion/fp_promo tion_2000_frep_08_en.pdf (2002, accessed 1 April 2019).

5. Steinert $T$ and Lepping $P$. Legal provisions and practice in the management of violent patients. a case vignette study in 16 European countries. Eur Psychiatry 2009;24:135-141.

6. Salize HJ and Dressing H. Epidemiology of involuntary placement of mentally ill people across the European Union. Br J Psychiatry 2004;184:163-168.

7. Zinkler $M$ and Priebe S. Detention of the mentally ill in Europe - a review. Acta Psychiatr Scand 2002;106:3-8.

8. European Union Agency for Fundamental Rights. Involuntary placement and involuntary treatment of persons with mental health problems. Vienna: European Union Agency for Fundamental Rights, 2012.

9. Mulder CL. Variations in involuntary commitment in the European Union. Br J Psychiatry 2005;187:91-92.

10. Lepping P, Steinert T, Gebhardt RP, et al. Attitudes of mental health professionals and lay-people towards involuntary admission and treatment in England and Germany - a questionnaire analysis. Eur Psychiatry 2004;19:91-95.

11. Israelsson M, Nordlof€ K and Gerdner A. European laws on compulsory commitment to care of persons suffering 
from substance use disorders or misuse problems - a comparative review from a human and civil rights perspective. Subst Abuse Treat Prev Policy 2015;10:34.

12. Georgieva I, Bainbridge E, McGuinness D, et al. Opinions of key stakeholders concerning involuntary admission of patients under the Mental Health Act 2001. Ir J Psychol Med 2017;34:223-232.

13. Steingberg D and Colla P. CART. Classification and regression trees. San Diego: Salford Systems, 1997.

14. Breiman L, Friedman J, Stone CJ, et al. Classification and regression trees. Belmont: Wadsworth International, 1984.

15. Agresti A. Categorical data analysis. Hoboken: John Wiley, 2013.

16. Georgieva I, Bainbridge E, McGuinness D, et al. Opinions of key stakeholders concerning involuntary admission of patients under the Mental Health Act 2001. Ir J Psychol Med 2017;34:223-232.

17. Wynn R. Involuntary admission in Norwegian adult psychiatric hospitals: a systematic review. Int J Ment Health Syst 2018;12:10.

18. World Health Organization. Mental health atlas 2014. Geneva: World Health Organization, 2014.
19. Gerlinger G, Deister A, Heinz A, et al. Nach der Reform ist vor der Reform. Ergebnisse der Novellierungsprozesse der Psychisch-Kranken-Hilfe-Gesetze der Bundesl€ander. [After the reform is before the reform: results of the amendment processes of mental health law in German federal states.] Der Nervenarzt 2019;90:45-57.

20. Lid B. Transport av psykiatriske pasienter: En kvalitativ studie av parørendes ${ }^{\circ}$ opplevelse av psykiatrisk ambulanse i Bergen og omegn: Norges teknisk-naturvitenskapelige universitet, Fakultet for samfunnsvitenskap og teknologiledelse, Institutt for sosialt arbeid og helseviten-skap, 2010.

21. Wyder M, Bland R and Crompton D. The importance of safety, agency and control during involuntary mental health admissions. J Ment Health 2016;25:338-342.

22. Festinger L. A theory of cognitive dissonance. Palo Alto: Stanford University Press, 1957.

23. Steinert $\mathrm{T}$, Lepping $\mathrm{P}$, Baranyai R, et al. Compulsory admission and treatment in schizophrenia. Soc Psychiatry and Psychiatr Epidemiol 2005;40:635-641. 